\title{
Correction to: Neural correlates of goal-directed enhancement and suppression of visual stimuli in the absence of conscious perception
}

\author{
Susan L. Travis ${ }^{1}$ - Paul E. Dux ${ }^{2}$ J Jason B. Mattingley ${ }^{1,2}$
}

Published online: 17 December 2018

(C) The Psychonomic Society, Inc. 2019, corrected publication 2019

\section{Correction to: Atten Percept Psychophys \\ https://doi.org/10.3758/s13414-018-1615-7}

The article Neural correlates of goal-directed enhancement and suppression of visual stimuli in the absence of conscious perception, written by Susan L. Travis, Paul E. Dux, and Jason B. Mattingley, was originally published electronically on the publisher's internet portal (currently SpringerLink) on 30 October 2018 with open access.

With the author(s)' decision to step back from Open Choice, the copyright of the article changed on 30 December 2018 to $(\subset$ The Psychonomic Society, Inc. 2018 and the article is forthwith distributed under the terms of copyright. The original article has been corrected.

Publisher's Note Springer Nature remains neutral with regard to jurisdictional claims in published maps and institutional affiliations.

The online version of the original article can be found at https://oi.org/ 10.3758/s13414-018-1615-7

Susan L. Travis

s.travis@uq.edu.au

1 Queensland Brain Institute, The University of Queensland, St Lucia, Queensland 4072, Australia

2 School of Psychology, The University of Queensland, St Lucia 4072, Australia 